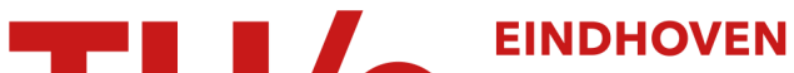 \\ UNIVERSITY OF \\ TECHNOLOGY
}

\section{Electrostatic and Sterical Stabilization of TiO2 Dispersions}

Citation for published version (APA):

Heijman, S. G. J., \& Stein, H. N. (1995). Electrostatic and Sterical Stabilization of TiO2 Dispersions. Langmuir, 11(2), 422-427. https://doi.org/10.1021/la00002a010

DOI:

10.1021/la00002a010

Document status and date:

Published: 01/01/1995

\section{Document Version:}

Publisher's PDF, also known as Version of Record (includes final page, issue and volume numbers)

\section{Please check the document version of this publication:}

- A submitted manuscript is the version of the article upon submission and before peer-review. There can be important differences between the submitted version and the official published version of record. People interested in the research are advised to contact the author for the final version of the publication, or visit the $\mathrm{DOI}$ to the publisher's website.

- The final author version and the galley proof are versions of the publication after peer review.

- The final published version features the final layout of the paper including the volume, issue and page numbers.

Link to publication

\section{General rights}

Copyright and moral rights for the publications made accessible in the public portal are retained by the authors and/or other copyright owners and it is a condition of accessing publications that users recognise and abide by the legal requirements associated with these rights.

- Users may download and print one copy of any publication from the public portal for the purpose of private study or research.

- You may not further distribute the material or use it for any profit-making activity or commercial gain

- You may freely distribute the URL identifying the publication in the public portal.

If the publication is distributed under the terms of Article $25 \mathrm{fa}$ of the Dutch Copyright Act, indicated by the "Taverne" license above, please follow below link for the End User Agreement:

www.tue.nl/taverne

Take down policy

If you believe that this document breaches copyright please contact us at:

openaccess@tue.nl

providing details and we will investigate your claim. 


\title{
Articles
}

\section{Electrostatic and Sterical Stabilization of $\mathrm{TiO}_{2}$ Dispersions}

\author{
S. G. J. Heijman and H. N. Stein \\ Eindhoven University of Technology, Faculty of Chemical Engineering, Laboratory of Colloid \\ Chemistry, P.O. Box 513, 5600 MB Eindhoven, The Netherlands
}

Received January 7, 1994. In Final Form: October 24, $1994^{\otimes}$

\begin{abstract}
The influence of polyacrylic acid (MW 2000-10 000) on the stability of $\mathrm{TiO}_{2}$ dispersions is investigated both in dilute suspensions (by light transmission) and in concentrated dispersions (by rheology). Polyacrylic acid in low concentrations destabilizes $\mathrm{TiO}_{2}$ dispersions, but at higher concentrations a stabilizing influence is found. In the high-concentration region, especially stable dispersions can be obtained when electrostatic and steric stabilization act simultaneously.
\end{abstract}

\section{Introduction}

Dispersions of inorganic solids such as $\mathrm{TiO}_{2}$ are widely used, e.g. in paints. In those applications, frequently a stable dispersion of the solids concerned is required. The size range of the primary particles of the pigment in most cases is adjusted such as to be in the optimum range with regard to light scattering as required for obtaining a paint of high covering power; in the case of $\mathrm{TiO}_{2}$, this is on the order of $0.3-0.4 \mu \mathrm{m}$. Aggregation of the pigment particles then should be avoided. This is achieved in most cases by the addition of polyelectrolytes acting as agents preventing coagulation. In such cases it is important to know under which conditions (concentrations, $\mathrm{pH}$, etc.) the polyelectrolyte will stabilize the pigment dispersion concerned, especially since low concentrations of a polyelectrolyte often bring about flocculation (aggregation due to polymer bridging) rather than counteract coagulation (aggregation under the influence of attractive Londonvan der Waals forces between the particles).

The question of the stabilization of colloid dispersions against aggregation by polyelectrolytes has been studied previously; see, for example, La Mer and Healy, ${ }^{1} \mathrm{Kitch}-$ ener, ${ }^{2}$ Vincent, ${ }^{3}$ and Burlamacchi et al. ${ }^{4}$ Usually, flocculation is induced by polyelectrolytes when their surface coverage is markedly below the saturation value of the surface; when the surface is covered to a higher degree, flocculation does not occur and stabilization against coagulation is brought about. Maximal flocculation is frequently achieved when the surface carries only about half its saturation capacity of polymer. ${ }^{2}$

While many aspects of these phenomena have been elucidated, there remain two questions which, in the opinion of the present authors, have as yet not received sufficient attention: (a) Are electrostatic and steric stabilization effects additive? In other words, if the surface charge and electrolyte concentration are such that a suspension is electrostatically stabilized against aggregate formation, is this stability of the dispersion then further enhanced by the presence of a polymer layer? (b) What stabilization/flocculation effects are observed on addition

$\otimes$ Abstract published in Advance ACS Abstracts, January 15, 1995.

(1) La Mer, V. K.; Healy, T. W. Rev. Pure Appl. Chem. 1963, 13, 112

(2) Kitchener, J. A. Br. Polym. J. 1972, 4, 217-229.

(3) Vincent, B. Adv. Colloid Interface Sci. 1974, 4, 193-277.

(4) Burlamacchi, L.; Ottaviani, M. F.; Ceresa, E. M.; Visca, M. Colloids Surf. 1983, 7, 165-182. of polyelectrolytes to more concentrated dispersions such as are used in practical circumstances?

The present study is devoted to these questions, in the special case of $\mathrm{TiO}_{2}$ as solid and polyacrylic acid (PAA) as polyelectrolyte. $\mathrm{TiO}_{2}$ volume fractions have been investigated both in a range that is dilute enough for following coagulation by light transmission $\left(\phi=2.7 \times 10^{-5}\right)$ and in a more concentrated range resembling those encountered in practical applications $(\phi=0.16-0.19)$.

\section{Experimental Section}

Materials. $\mathrm{TiO}_{2}$. Two samples were used, both having the crystal structure of rutile.

(a) One sample was prepared by the Bérubé and de Bruyn method, ${ }^{5}$ starting from $\mathrm{TiCl}_{4}$ from Fluka (pro analysi). Electron microscopy showed that the particles were needles with dimensions of about $15 \times 15 \times 150 \mathrm{~nm}$. Its surface area, as determined by the BET method with $\mathrm{N}_{2}$ as adsorbate, was $28 \mathrm{~m}^{2} / \mathrm{g}$. The point of zero charge (measured as a common intersection point of $\mathrm{TiO}_{2}$ suspensions in solutions with different electrolyte concentrations ${ }^{11}$ ) and isoelectric point (IEP, measured as the $\mathrm{pH}$ at which there is no electrophoretic velocity ${ }^{11}$ ) of the sample coincided at $\mathrm{pH}=5.7$.

(b) The other sample was prepared by the "chloride" process, using $\mathrm{TiCl}_{4}$ obtained from Tiofine. It had been without application of a coating. The IEP was found at $\mathrm{pH}=6.0$. The particles were nearly spherical (slightly ellipsoidal) with diameter ratios (as seen in TEM micrographs) of about 1.2 and diameters varying between about 100 and $200 \mathrm{~nm}$.

Polyacrylic Acid (PAA). Three samples were used: (a) a homopolymer of acrylic acid from Janssen Chemical, molecular weight $\left(M_{\mathrm{W}}\right) 2000 ; \mathrm{H}^{+}$counterion; (b) a homopolymer of acrylic acid from Servo (Delden, The Netherlands) type FX504, $M_{\mathrm{W}}$ $10000 ; \mathrm{NH}_{4}{ }^{+}$counterion; and (c) a copolymer of acrylic acid (90\%) and styrene (10\%) from Servo, type FX 508, $M_{\mathrm{W}} 11000 ; \mathrm{NH}_{4}^{+}$ counterion.

$\mathrm{KNO}_{3}$ was analytical reagent grade.

Methods. Coagulation rates were followed by light transmission, by means of a Vitatron MPS spectrophotometer provided with a magnetically stirred cylindrical vessel (i.d. $7 \mathrm{~mm}$ ). Before measurement, the $\mathrm{TiO}_{2}$ was dispersed in water or PAA solution, 305 .

(5) Bérubé, Y. G.; de Bruyn, Ph. L. J. Colloid Interface Sci. 1968, 27,

(6) Lyklema, J.; Fleer, G. J. Colloids Surf. 1987, 25, 357.

(7) Heijman, S. G. J Oxide Pigments in Water: the Colloid Chemical Point of View. Ph.D. Thesis, Eindhoven, 1993.

(8) Heijman, S. G. J.; Stein, H. N. Chem. Eng. Sci. 1993, 48, 313. 231

(10) Vedula, R. R.; Spencer, H. G. Colloids Surf. 1991, 58, 99-110.

(11) Janssen, M. J. G.; Stein, H. N. J. Colloid Interface Sci. 1986, $109,508-515$ 


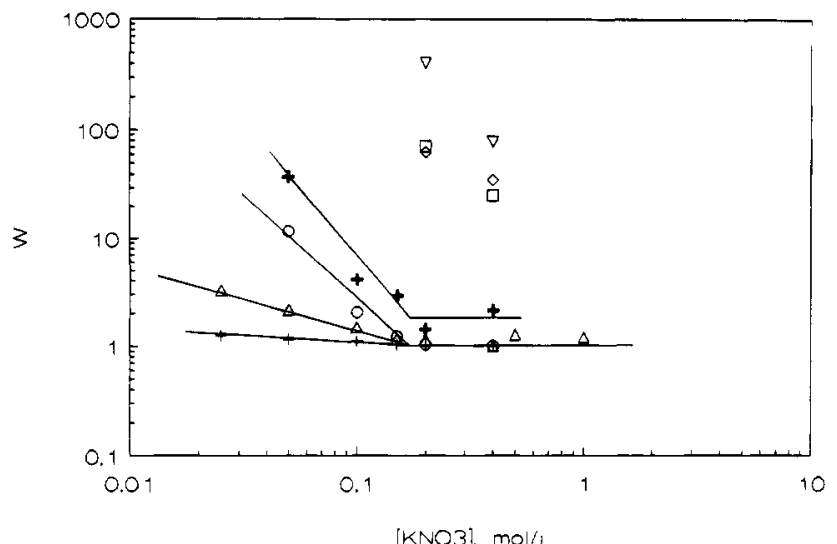

Figure 1. Experimental stability ratios in low volume fraction $\left(\phi=2.7 \times 10^{-7}\right) \mathrm{TiO}_{2}$ dispersions, as a function of $\mathrm{KNO}_{3}$ concentration for different quantities of PAA added. Quantities of PAA added are expressed as grams per square meter of pigment surface area: $\mathrm{TiO}_{2}$, sample a; PAA, sample a; $\mathrm{pH}=$ $6.0 ;+, 0 \mathrm{~g} / \mathrm{m}^{2} ; \Delta, 2.8 \times 10^{-5} \mathrm{~g} / \mathrm{m}^{2} ; 0,2.2 \times 10^{-4} \mathrm{~g} / \mathrm{m}^{2} ;+, 3.5 \times$ $10^{-4} \mathrm{~g} / \mathrm{m}^{2} ; \square, 4.2 \times 10^{-4} \mathrm{~g} / \mathrm{m}^{2} ; \diamond, 4.9 \times 10^{-4} \mathrm{~g} / \mathrm{m}^{2} ; \nabla, 5.9 \times 10^{-4}$ $\mathrm{g} / \mathrm{m}_{2}$.

using an Ystral X40/38 colloid mill (volume fraction of $\mathrm{TiO}_{2}, 2.7$ $\left.\times 10^{-5}\right)$. Electrolyte $\left(\mathrm{KNO}_{3}\right)$ was added at time $t=0$. From the light transmission vs time graphs, stability factors for the dispersions were calculated by assuming an absence of electrostatic and sterical repulsion in PAA free dispersions with $\left[\mathrm{KNO}_{3}\right]$ $>0.15 \mathrm{M}$; this assumption was confirmed by equal initial light transmission vs time rates at all $\left[\mathrm{KNO}_{3}\right]$ values exceeding 0.15 $\mathrm{M}$, in the absence of PAA. Thus the critical coagulation concentration in $\mathrm{KNO}_{3}$ solutions was found for the $\mathrm{TiO}_{2}$ sample employed here to be $0.15 \mathrm{M}$. A stability ratio $(W)$ for other concentrations of $\mathrm{KNO}_{3}$ and/or PAA was then defined as the quotient of the coagulation rate in the absence of electrostatic and steric repulsion and of the coagulation rate in the presence of either or both stabilizing effects. The stability ratio is found as the ratio of the rate of decrease of the light transmission observed in the presence of $\left[\mathrm{KNO}_{3}\right]>0.15 \mathrm{M}$ and in the absence of PAA to that found for the other conditions. Thus, the influence of uncertainties in the effective shear rates present during the coagulation experiments was eliminated.

Viscosity was measured in a sample of a $\mathrm{TiO}_{2}$ dispersion (solid volume fraction of $0.16-0.19$ ), prepared by mixing and dispersing the appropriate amount of $\mathrm{TiO}_{2}$ in about $1 \mathrm{~L}$ of water, during 1 min in an Ystral X40/38 colloid mill. This dispersion is indicated as bulk dispersion. Viscosity measurements were performed in a Contraves Rheomat 115 viscometer, with a rotating bob and a thermostated cup with dimensions according to DIN 145. During measurements, the shear stress was raised starting from 10 to $343 \mathrm{~s}^{-1}$, then it was lowered. The measured sample was then returned to the bulk dispersion, and additional PAA was added. From the measurements a viscosity was calculated as the quotient (shear stress)/(shear rate), assuming a shear rate distribution in the viscometer as for a Newtonian liquid. In agreement with rheological nomenclature, this viscosity is indicated here as "apparent" viscosity.

Adsorption isotherms were obtained by adding a solution of poly(acrylic acid) with the required $\mathrm{pH}$ and ionic strength to a suspension of $\mathrm{TiO}_{2}$ with the same $\mathrm{pH}$ and ionic strength. After $1 \mathrm{~h}$ of agitation the $\mathrm{pH}$ was adjusted. After $20 \mathrm{~h}$ of agitation at $25^{\circ} \mathrm{C}$, the suspension was centrifuged and the concentration of the PAA was measured in the supernatant using a total organic carbon analyzer (O.I. Analytica Model 700). Blank tests indicated very little organic species passing into the solution from the solid $(<0.1 \mathrm{ppm}$ in the equilibrium solution). The $\mathrm{pH}$ of the supernatant was always within $\pm 0.1 \mathrm{pH}$ unit of the desired $\mathrm{pH}$.

\section{Results and Discussion}

A. Dilute $\mathrm{TiO}_{2}$ Dispersions $\left(\phi=2.5 \times 10^{-7}\right)$. At low [PAA] values, the stability factor $W$ is found to behave, as a function of electrolyte concentration, as reported in similar cases ${ }^{6}$ (see Figures 1 and 2). The [PAA] is indicated

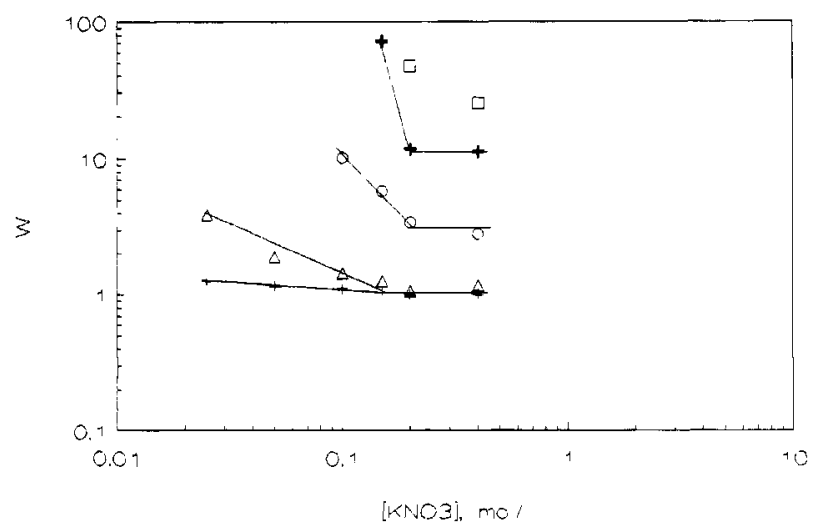

Figure 2. Conditions as in Figure 1, except with PAA sample c instead of sample a:,$+ 0 ; \Delta, 1.2 \times 10^{-4} \mathrm{~g} / \mathrm{m}^{2} ; 0,2.4 \times 10^{-4}$ $\mathrm{g} / \mathrm{m}^{2} ;+, 3.2 \times 10^{-4} \mathrm{~g} / \mathrm{m}^{2} ; \square, 4.7 \times 10^{-4} \mathrm{~g} / \mathrm{m}^{2}$.

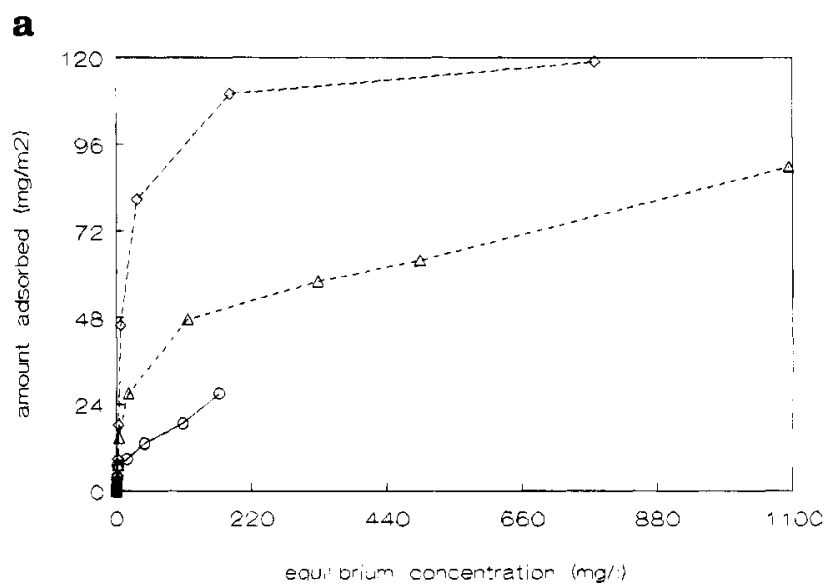

b

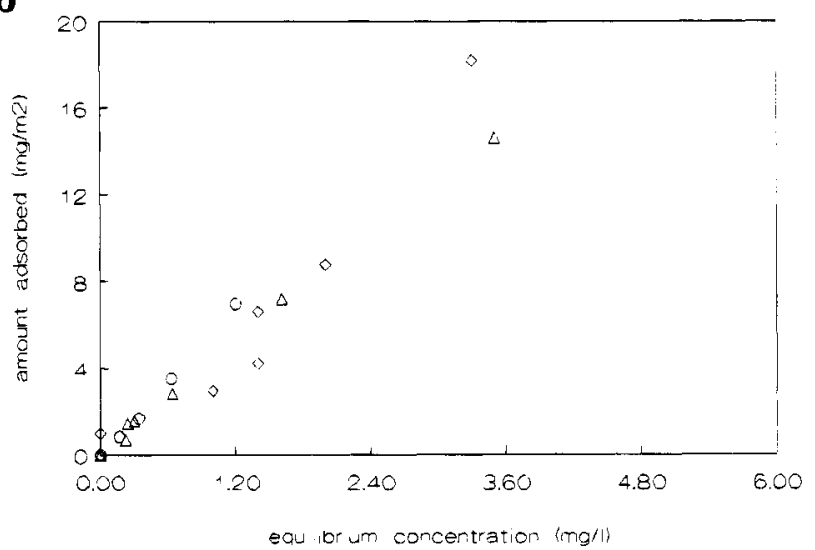

Figure 3. Adsorption of $\mathrm{PAA}$ sample a on $\mathrm{TiO}_{2}$ sample a: $\diamond$ $\mathrm{pH}=4.2 ; \Delta, \mathrm{pH}=5.3 ; \mathrm{O}, \mathrm{pH}=6.5 ;$ (a) overview; (b) low concentration region on enlarged scale.

in these figures as grams of PAA per square meter of $\mathrm{TiO}_{2}$ surface. This appears to be the most appropriate way of expressing the quantity of PAA added since separate experiments showed that, for the $\mathrm{PAA}$ and $\mathrm{TiO}_{2}$ samples employed here, there is, at low [PAA], virtually complete adsorption of PAA on $\mathrm{TiO}_{2}{ }^{7,8}$ (see Figure 3 ).

These adsorption measurements show distinctly a transition from a high-affinity region at low PAA concentrations in the solution and low degrees of coverage of the $\mathrm{TiO}_{2}$ surface by PAA to a lower affinity range in which the slope of the curve of adsorbed PAA against the concentration is smaller. The existence of a high-affinity range agrees with data reported by Gebhardt and Fuerstenau ${ }^{9}$ but stands in contrast with data reported by Vedula and Spencer ${ }^{10}$ and by Burlamacchi et al. ${ }^{4}$ The difference with the data reported by Vedula et al. and by 
Burlamacchi et al. is the much higher affinity of the polyacrylic acid toward the $\mathrm{TiO}_{2}$ surface in our case. These differences can be ascribed to differences between the $\mathrm{TiO}_{2}$ samples employed by the respective investigators: Vedula et al. and Burlamacchi et al. employed commercial samples presumably manufactured by the so-called "sulfate" process starting from $\mathrm{Ti}\left(\mathrm{SO}_{4}\right)_{2}$. This appears in the case of the sample used by Burlamacchi et al. from the release of $\mathrm{SO}_{4}{ }^{2-}$ ions by the $\mathrm{TiO}_{2}$ sample in aqueous solution reported by these authors. Vedula and Spencer used $\mathrm{TiO}_{2}$ with an anatase structure, which cannot be made by the "chloride" process starting from $\mathrm{TiCl}_{4}$, because in this process rutile is formed directly while in the sulfate process first anatase is formed which may be converted later into rutile. $\mathrm{TiO}_{2}$ samples made by the sulfate process almost invariably contain chemically bound sulfate ions at their surface which are very persistent and cannot be totally removed by washing or soxhlet extraction and manifest themselves in the final $\mathrm{TiO}_{2}$ as chemisorbed ions, as reported by Janssen and Stein. ${ }^{11}$ Therefore in the present investigation, $\mathrm{TiO}_{2}$ samples used were prepared from $\mathrm{TiCl}_{4}$ either in the laboratory or commercially, which are less prone to uptake of ions during their manufacture. The absence of chemisorbed anions in the case of our $\mathrm{TiO}_{2}$ samples has been shown by the coincidence of PZC and IEP.

In addition, in our adsorption data no plateau region of constant adsorption is reached, as reported by Gebhardt and Fuerstenau. However, the existance of the plateau is not well-established by the experiments shown by Gebhardt and Fuerstenau, due to the spread in their adsorption data at high concentrations.

Data in the high-affinity adsorption region are plotted on an enlarged scale in Figure $3 \mathrm{~b}$. It is seen that, in this concentration range, the tendency of PAA to become adsorbed at a given concentration does not depend on the surface charge on the $\mathrm{TiO}_{2}$, but it should be remembered that the charge on the PAA also changes with changing $\mathrm{pH}$. This stands in contrast with the situation at higher concentrations, in which a positive surface charge of increasing absolute value stimulates the adsorption of the anionic polyelectrolyte (Figure $3 a$ ). However, the total amount which can be accomodated at the surface in the high adsorption range increases with decreasing $\mathrm{pH}$ value, i.e. with increasing absolute value of the surface charge if the latter is positive.

When there is virtually complete adsorption, it is more important to know how much PAA is present per square meter of $\mathrm{TiO}_{2}$ surface area than to know what the residual concentration in the liquid is. At $\left[\mathrm{KNO}_{3}\right]>0.15 \mathrm{M}, W$ values of 1 are found (as follows from the definition of $W$ employed here); at $\left[\mathrm{KNO}_{3}\right]<0.15 \mathrm{M}, W$ increases as a result of increasing electrostatic repulsion. In the absence of PAA, the increase of $W$ with decreasing $\left[\mathrm{KNO}_{3}\right]$ is only slight, which is to be expected since the $\mathrm{TiO}_{2}$ is very near its IEP. Low [PAA] values lead to higher stabilities against coagulation (increasing $W$ values) since the PAA is adsorbed and increases the $\zeta$ potential in an absolute sense (Figure 4). However, at low [PAA] values, there is no significant slowing down of the coagulation at $\left[\mathrm{KNO}_{3}\right]>$ $0.15 \mathrm{M}$, which indicates the absence of steric stabilization. Such slowing down of the coagulation at $\left[\mathrm{KNO}_{3}\right]>0.15$ $\mathrm{M}$ is observed at higher [PAA] values, indicating that under these conditions there is steric repulsion between the $\mathrm{TiO}_{2}$ particles.

Figure 5 shows the $W$ values found at $\left[\mathrm{KNO}_{3}\right]=0.4 \mathrm{M}$, definitely above the concentration range in which electrostatic repulsion is expected. Thus, in this graph the sterical repulsion is shown; in agreement with the statements in the previous paragraph, there is some

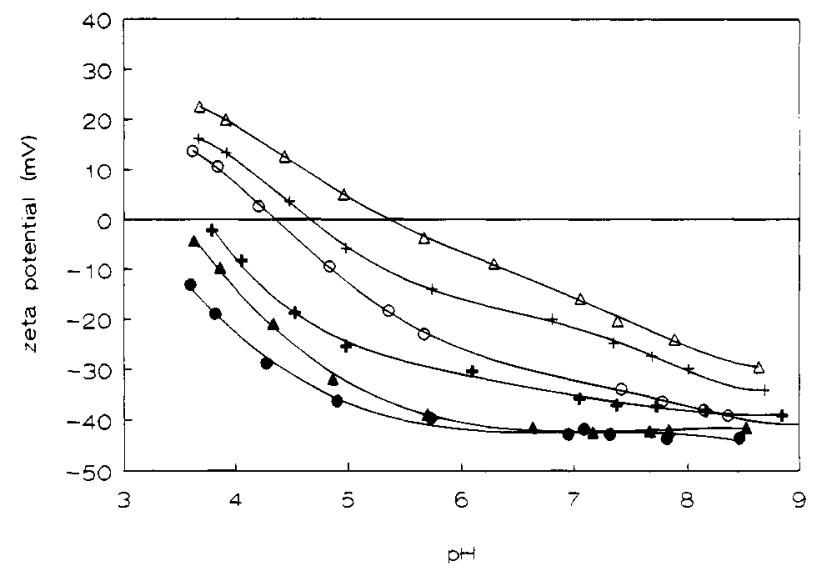

Figure 4. $\zeta$ potential as a function of $\mathrm{pH}$, for different quantities of PAA added: $\mathrm{TiO}_{2}$, sample a; PAA, sample a; $\triangle, 0 \mathrm{~g} / \mathrm{m}^{2}$; , $0.09 \times 10^{-4} \mathrm{~g} / \mathrm{m}^{2} ; 0,0.35 \times 10^{-4} \mathrm{~g} / \mathrm{m}^{2} ;+, 0.71 \times 10^{-4} \mathrm{~g} / \mathrm{m}^{2} ; \Delta$ $1.4 \times 10^{-4} \mathrm{~g} / \mathrm{m}^{2} ; 0,2.8 \times 10^{-4} \mathrm{~g} / \mathrm{m}^{2} .\left[\mathrm{KNO}_{3}\right]=0.01 \mathrm{M}$.

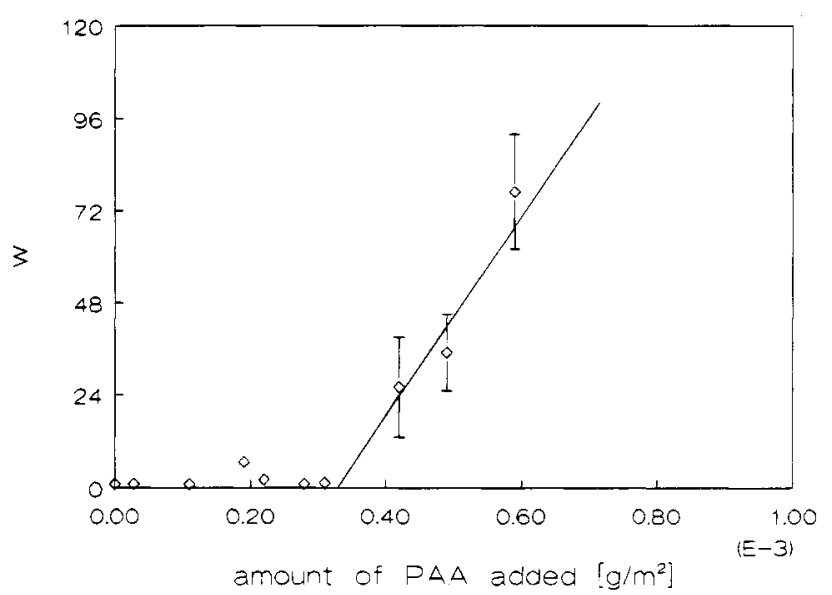

Figure 5. Experimental stability ratios as a function of the quantity of PAA added, at $\left[\mathrm{KNO}_{3}\right]=0.4 \mathrm{M}$ : $\mathrm{TiO}_{2}$, sample a; PAA, sample $a ; \mathrm{pH}=6.0$.

minimal value of [PAA] which should be surpassed for sterical repulsion to become noticeable. In Figure 5, values are shown only for the PAA sample a, but with samples $\mathrm{b}$ and $\mathrm{c}$, the same trend was observed.

High Solid Volume Fraction $(\phi=0.16-0.19)$. In the experiments related to the high concentration range of $\mathrm{TiO}_{2}$, the final PAA concentration in the liquid phase is expressed again as the quantity added per square meter of $\mathrm{TiO}_{2}$ surface.

Figure 6 shows that the pastes were shear rate thinning, especially at low [PAA]. This shear rate thinning character of the pastes can be attributed to the breaking up of flocs under shear. Especially at low [PAA], some thixotropy (decrease of viscosity with time at constant shear rate) is observed; this confirms the flocculated state of the suspensions under these conditions.

Figure 7 shows the apparent viscosity of the suspensions and the $\zeta$ potential of the solid phase at various [PAA] values. Low [PAA] values are seen to effect a distinct increase in apparant viscosity; this can be attributed to increased coagulation of the $\mathrm{TiO}_{2}$, by bridging flocculation. That this aggregation mechanism is the prevailing one follows from two arguments: (a) at the [PAA] values concerned, the surfaces of $\mathrm{TiO}_{2}$ are only partially covered by $\mathrm{PAA}^{7,8}$ while there is virtually complete removal of dissolved PAA from the solution by adsorption; (b) with increasing [PAA], the viscosity passes through a maximum and decreases again to very low values. This indicates absence of coagulation at large [PAA] values, contradicting 


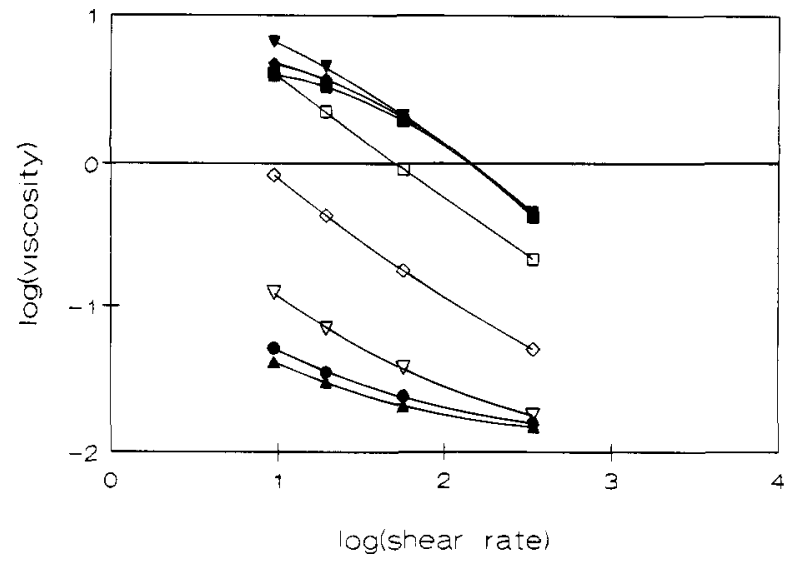

Figure 6. Apparent viscosities at steady shear rate, as a function of the shear rate, at different quantities of PAA added: $\mathrm{TiO}_{2}$, sample b; PAA, sample b; $\mathrm{pH}=6.1 ; \mathrm{a}, 0 \mathrm{~g} / \mathrm{m}^{2} ;, 1 \times 10^{-6}$ $\mathrm{g} / \mathrm{m}^{2} ; \nabla, 3 ; \square, 5 \times 10^{-6} ; \diamond, 7 \mathrm{~g} / \mathrm{m}^{2} ; \nabla, 9 \times 10^{-6} \mathrm{~g} / \mathrm{m}^{2} ; 11 \times 10^{-6}$ $\mathrm{g} / \mathrm{m}^{2} ; \Delta, 15 \times 10^{-6} \mathrm{~g} / \mathrm{m}^{2}$

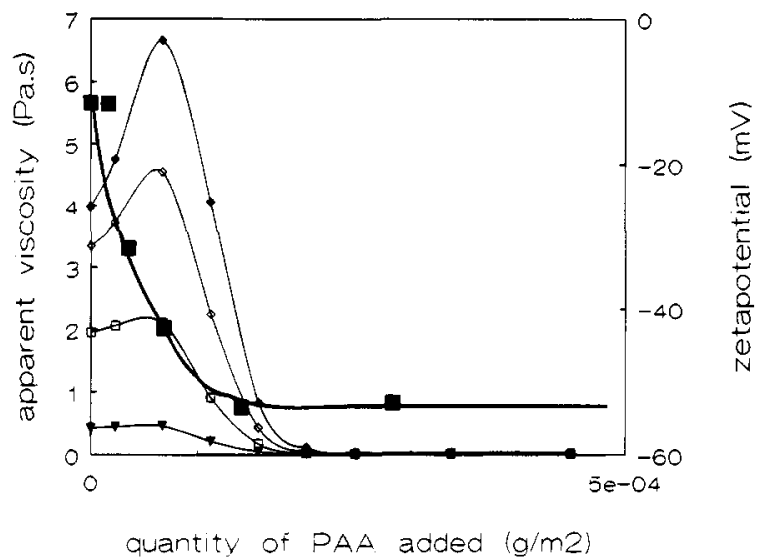

Figure 7. Left hand scale: Apparent viscosities at constant shear rate, of $\mathrm{TiO}_{2}$ dispersions (volume fraction, 0.16), for different values of the shear rate $\left(\bullet, 10 \mathrm{~s}^{-1} ; \diamond, 20 \mathrm{~s}^{-1} ; \square, 60 \mathrm{~s}^{-1}\right.$; $\nabla, 343 \mathrm{~s}^{-1}$ ). Right hand scale: ( $\mathbf{\square}$ ) zeta potential, as a function of quantity of PAA added. Concentrations of PAA are expressed as grams per square meter of $\mathrm{TiO}_{2}$ surface area: $\mathrm{TiO}_{2}$, sample b; PAA, sample b; $\mathbf{p H}=6.1$.

coagulation by depletion of polyelectrolyte between two approaching particles. The occurrence of coagulation at low PAA concentrations and its absence at higher concentrations is confirmed by the decrease in shear rate thinning character observed (Figure 6).

Very low values of the viscosity are reached when the absolute value of the $\zeta$ potential reaches a constant value $(-55 \mathrm{mV})$. Under these circumstances, coagulation is counteracted by electrostatic stabilization. This is likely to be important because it is determined by the electrolyte concentration at large distances from the solid particles ${ }^{12}$ which is very low because no electrolyte had been added to the paste apart from the PAA and because in the pastes concerned the quantity of PAA in the continuous phase is negligible because of nearly complete adsorption of the PAA on the $\mathrm{TiO}_{2}$.

Sterical stabilization of the $\mathrm{TiO}_{2}$ under the conditions just after passage, with increasing [PAA], of the viscosity peak is unlikely: in the range of the PAA quantities added, the amount of PAA adsorbed on the $\mathrm{TiO}_{2}$ still increases.

Upon closer inspection, the low viscosity value observed at concentrations higher than those corresponding to the viscosity peak is not constant but increases again with a

(12) Overbeek, J. Th. G. In Colloid Science; Kruyt, H. R., Ed.; Elsevier Publ. Co.: Amsterdam, 1952; Vol. I, p 128-130.

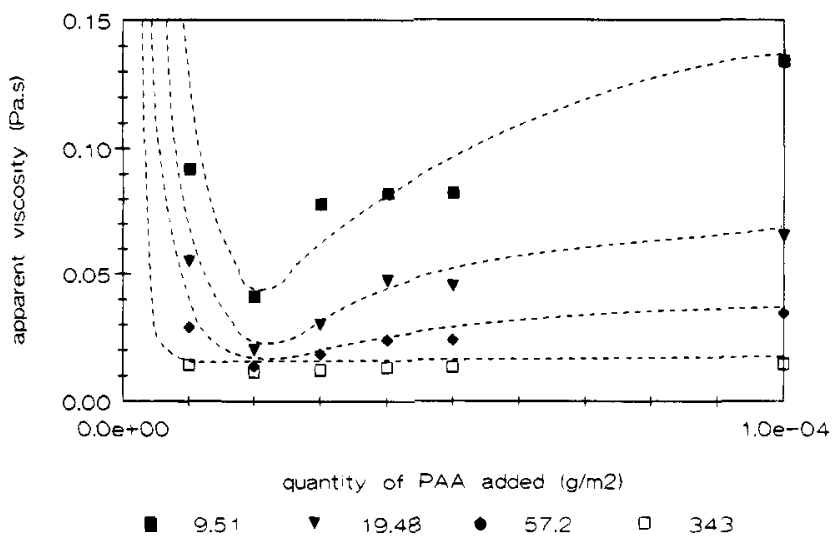

Figure 8. Apparent viscosities as in Figure 7, on a different scale showing the increase of apparent viscosity for large quantities of added PAA.

further increase in the amount of PAA added (Figure 8). The data in this figure refer to measurements at $\mathrm{pH}=$ 6.1, very near the IEP of the $\mathrm{TiO}_{2}$ sample concerned, but essentially similar graphs were obtained at $\mathrm{pH}$ values both below and above the IEP, even at $\mathrm{pH}$ values at which the surface charge of the $\mathrm{TiO}_{2}$ in the absence of PAA is large enough to effect a noticeable stabilization against coagulation. ${ }^{7}$ The increased viscosity of the continuous phase being caused by the presence of free PAA at high [PAA] is excluded by the adsorption measurements showing that the free PAA concentration is too small for any noticeable viscosity increase. As fas as we can see, there are two possible explanations left for this viscosity increase: (a) When large quantities of PAA are added to the paste, there is no more total adsorption of PAA on the $\mathrm{TiO}_{2}$ surface. ${ }^{7,8}$ Dissolved PAA may induce depletion coagulation. ${ }^{13}$ (b) At large concentrations of PAA, the surface layers consisting of adsorbed PAA are thick enough for their contribution to the total volume of the suspension to become important. Thus, the effective solid volume fraction of the dispersion is increased, which leads to an increase in apparant viscosity.

Calculations of the depletion interaction induced by the presence of PAA at the relevant concentrations do not support alternative a. Such calculations require a $\mathrm{Ha}$ maker constant to be introduced. It appears that there is no complete agreement on the Hamaker constant of $\mathrm{TiO}_{2}$ in aqueous solutions; values ranging from $2.5 \times 10^{-20}$ to $10 \times 10^{-20} \mathrm{~J}$ having been reported.14 We will not introduce much error if we assume a Hamaker constant in the range $0.5-5 \times 10^{-20} \mathrm{~J}$ (see also Hamaker constants reported for other oxides ${ }^{14}$ ). In Figure 9, the total interaction energy between $\mathrm{TiO}_{2}$ particles is plotted, as a function of the shortest intersurface distance between two spherical particles with radius $1.5 \times 10^{-7} \mathrm{~m}$, using Hamaker constants of $5 \times 10^{-21}$ and $5 \times 10^{-20} \mathrm{~J}$ and $\mathrm{a}$ Stern potential of $-55 \mathrm{mV}$. The attractive potential energy has been calculated using the Clayfield et al. ${ }^{15}$ formulae for partially retarded attraction between spherical particles, which give results that are nearly identical with those given by the Schenkel and Kitchener equations. ${ }^{16}$ The repulsive interaction energy was calculated by Derjaguin's method ${ }^{17}$ and the depletion interaction by the Sperry formula. ${ }^{18}$ For calculating the osmotic pressure of

(13) Prestidge, C.; Tadros, Th. F. Colloids Surf. 1988, 31, 325.

(14) Visser, J. Adv. Colloid Interface Sci. 1972, 3, 331-363.

(15) Clayfield, E. J.; Lumb, E. C.; Mackay, P. H. J. Colloid Interface Sci. 1971, 37, 382

(16) Schenkel, J. H.; Kitchener, J. A. Trans. Far. Soc. 1960, 56, 161.

(17) Derjaguin, B. Kolloid-Z. 1934, 69, 155; Acta Physicochim. USSR $1939,10,333$.

(18) Sperry, P. R. J. Colloid Interface Sci. 1982, 87, 375. 


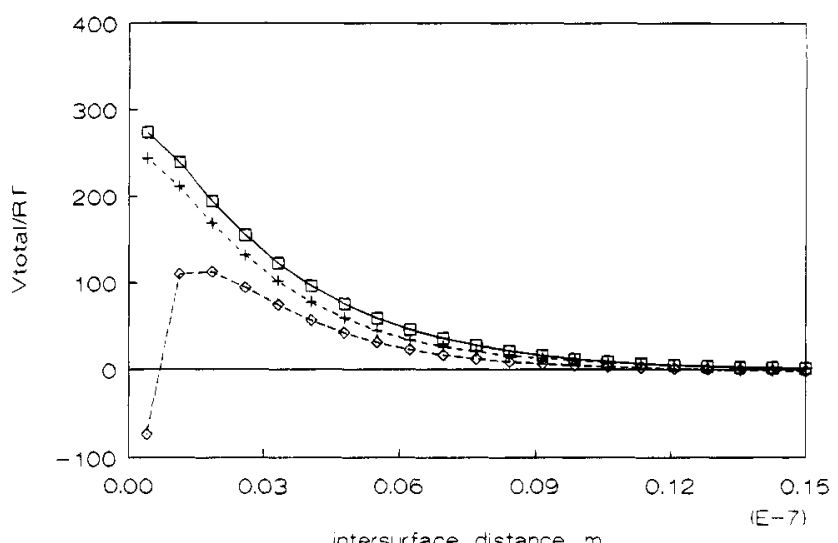

Figure 9. Interaction energy between two spherical $\mathrm{TiO}_{2}$ particles, as a function of intersurface distance, at a PAA concentration in solution corresponding to $0.3 \mathrm{~g}$ of PAA added per $\mathrm{m}^{2}$ of $\mathrm{TiO}_{2}$ surface. The PAA concentration in solution is then $1 \mathrm{~g} / \mathrm{L} . \quad \psi_{\delta}=-55 \mathrm{mV}$; [electrolyte, $1: 1$ ] $=0.0139 \mathrm{M}$; osmotic coefficient of PAA $=0.24 ; \square, A_{\text {Hamaker }}=0.5 \times 10^{-20} \mathrm{~J}$; radius of gyration of dissolved PAA $\left(R_{\mathrm{g}}\right)=4 \times 10^{-9} \mathrm{~m}^{\prime} ;+, A_{\text {Hamaker }}=0.5$ $\times 10^{-20} \mathrm{~J} ; R_{\mathrm{g}}=5.6 \times 10^{-9} \mathrm{~m} ; \diamond, A_{\text {Hamaker }}=5 \times 10^{-20} \mathrm{~J} ; R_{\mathrm{g}}=$ $5.6 \times 10^{-9} \mathrm{~m}$.

the PAA solution, PAA was considered as behaving like a monomer, sodium acrylate, but with an osmotic coefficient of 0.24 as reported for highly charged polyelectrolytes in the concentration range concerned..$^{19-21}$ For the radius of gyration, an upper limit is $5.6 \times 10^{-4} \mathrm{~m}$ (which corresponds to half the total length of a fully stretched PAA chain of a PAA molecule with $M_{\mathrm{W}}=2000$ ). The result is influenced only slightly by the radius of gyration, which is assumed for the PAA molecule, or by the value of the Hamaker constant assumed for $\mathrm{TiO}_{2}$. The value of the Hamaker constant influences, however, the value of the interaction energy at the secondary minimum: if $A_{\text {Hamaker }}=1 \times 10^{-20} \mathrm{~J}$, it is $-0.22 \mathrm{kT}$, while for $A_{\text {Hamaker }}=1 \times 10^{-19} \mathrm{~J}$, a secondary minimum of about -4 $\mathrm{kT}$ in the interaction energy is found.

Alternative $b$, on the other hand, is supported by the following argument: The thickness of the adsorbed polyelectrolyte layer can be calculated from the viscosity, if the latter can be used to estimate the solid volume fraction. The thickness of the adsorbed layer in the case of concentrated dispersions can also be estimated from a different experimental quantity: from the permeability of a $\mathrm{TiO}_{2}$ paste. If both values prove to be equal, with regard to their order of magnitude, alternative $b$ is supported. In order for the comparison between both values to be valid, it is important that the solid volume fraction be comparable in the rheological experiments, on the one hand, and in the premeability measurements, on the other. This excludes estimation of the adsorbed layer thickness through viscosity measurements in very dilute suspensions, in which the Einstein equation can be applied: in such very dilute suspensions, the adsorbed layer thickness is expected to differ systematically from that in more concentrated dispersions, since bridging between two $\mathrm{TiO}_{2}$ particles will occur in both concentration regions to a different degree.

Since we are dealing here with dispersions with solid volume fractions which are higher than the solid volume fraction region in which the Einstein equation can be reasonably applied but which are still much lower than that corresponding to the maximum solid volume fraction 85 .

(19) Kozak, D.; Kristan, J.; Dolar, D. Z. Phys. Chem. N. F. 1971, 76,

(20) Rinaudo, M.; Mazet, J.; Milas, M. C. R. Acad. Sci. Paris C 1973, 276,1401 .

(21) Lifson, S.; Katchalsky, A. J. Polym. Sci. 1953, 13, 43.

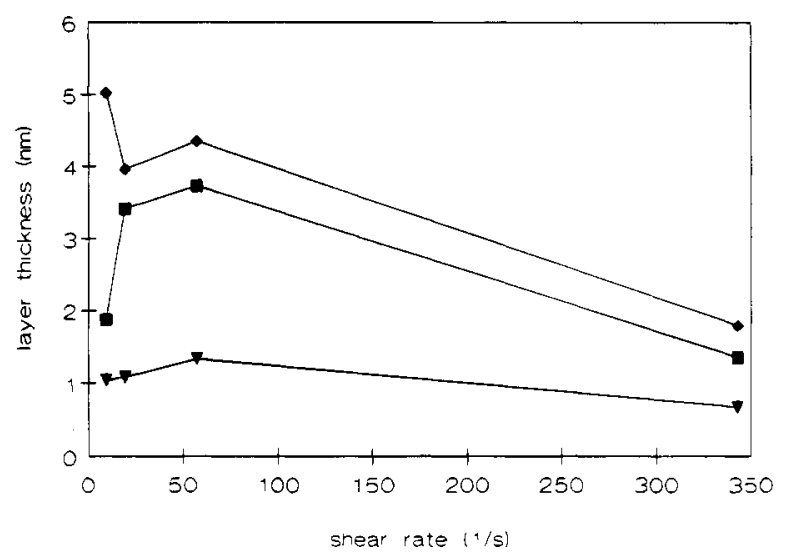

Figure 10. Hydrodynamic layer thickness calculated from the viscosity increase on adding $0.6 \mathrm{wt} \%$ PAA to pastes at the viscosity minimum of Figures 6 and 7 , as a function of shear rate: $\mathbf{\square}, \mathrm{pH}=6.1 ; \diamond, \mathrm{pH}=10.5 ; \nabla, \mathrm{pH}=4.0$.

permitting shear (which is, for a dispersion of monodisperse spherical particles of nearly the same size, about $0.63^{22}$ ), we assume here that the Dougherty-Krieger equation is valid:

$$
\eta_{\mathrm{r}}=\left(1-\frac{\varphi}{\varphi_{\max }}\right)^{-\eta \phi_{\max }}
$$

with $\eta=$ the intrinsic viscosity, assumed to be $2.50 ; \phi=$ the solid volume fraction; $\phi_{\max }=$ the maximum volume fraction at which shear is possible (assumed to be $0.6^{22}$ ); and $\eta_{\mathrm{r}}=$ the relative viscosity.

In using the Dougherty-Krieger relation between relative viscosity and solid volume fraction, the approximation that the particles, though needle-shaped, affect viscosity as if they were spherical is introduced. This relates especially to the value of 2.5 assumed for the intrinsic viscosity, $\eta$. This value, though certainly not exact, probably does not lead to large errors as long as the increase in solid volume fraction concerned is small and the solid volume fraction is far from the maximum solid volume fraction at which flow is possible. To be sure, the resulting layer thickness cannot be regarded as more certain than 1 order of magnitude; but a greater certainty is not claimed in the context of the present paper.

The Dougherty -Krieger relation leads to the following equation for the effective solid volume fraction at a given viscosity:

$$
\varphi=\frac{\eta_{\mathrm{r}}^{0.67}-1}{\frac{\eta_{\mathrm{r}}^{0.67}}{0.6}}
$$

The solid volume fraction varies with the third power of the dimensions of the particles; if the particles are approximated as spheres, an increase of the relative viscosity from $\eta_{1}$ to $\eta_{2}$ can be recalculated as an increase in particle radius with the formula

$$
\frac{\mathbf{r}_{1}^{3}}{r_{2}{ }^{3}}=\frac{\varphi_{1}}{\varphi_{2}}=\frac{\left(\eta_{1}^{0.67}-1\right) \eta_{2}^{0.67}}{\left(\eta_{2}{ }^{0.67}-1\right) \eta_{1}{ }^{0.67}}
$$

with $\eta_{1}=$ the relative viscosity without the polymer layer and $\eta_{2}=$ the relative viscosity with the polymer layer.

This gives values for the hydrodynamic layer thickness of adsorbed PAA shown in Figure 10. The values

(22) Schreuder, F. W. A. M.; van Diemen, A. J. G.; Stein, H. N. J. Colloid Interface Sci. 1986, 111, 35 . 
mentioned in this figure agree, as to their order of magnitude, with the values calculated for the hydrodynamic layer thickness under similar conditions, from the permeability reduction of a porous bed consiting of $\mathrm{TiO}_{2}$ by adsorbed PAA. ${ }^{7}$ A hydrodynamic layer thickness of 3 $\mathrm{nm}$ containing $5 \times 10^{-4} \mathrm{~g}$ of PAA per square meter of surface (as found from adsorption measurements) has a PAA volume fraction of about $17 \%$; this appears to be compatible with immobilization of the solvent.

It may come as a surprise that a layer of only a few nanometers thickness can effect sterical stabilization and may greatly increase the electrostatic repulsion at low electrolyte concentrations. However, an influence of such a thin adsorbed layer is confirmed by calculations of the perikinetic stability ratio $(W)$ at different electrolyte concentrations. $W$ can be calculated by the formula ${ }^{6,7}$

$$
W=\frac{\int_{0}^{\infty} \frac{\beta(u)}{(2+u)^{2}} \exp \left(\frac{V_{\mathrm{a}}+V_{\mathrm{r}}}{k T}\right) \mathrm{du}}{\int_{0}^{\infty} \frac{\beta(u)}{(2+u)^{2}} \exp \left(\frac{V_{\mathrm{a}}}{k T}\right) \mathrm{du}}
$$

where $V_{\mathrm{a}}=$ the van der Waals attractive energy, $V_{\mathrm{r}}=$ the repulsive energy, $\beta(u)=$ the hydrodynamic correction factor, and $u=$ the shortest distance between the particle surfaces divided by the particle radius. In these calculations, Hamaker constants of $5 \times 10^{-21}$ and $5 \times 10^{-20} \mathrm{~J}$ were used for $\mathrm{TiO}_{2}$. The hydrodynamic layer was regarded as indistinguishable, with regard to London-van der Waals interaction, from the solvent (about $83 \%$ of its volume is made up of solvent molecules). Thus, it was assumed, in agreement with calculations reported by Osmond et al., ${ }^{23}$ that an adsorbed layer acts primarily through the "core spacing" effect. Electrostatic repulsion was taken into account, approximating Stern potentials by experimental value of $\xi$ potentials, with the Derjaguin formula ${ }^{17}$ if the absolute value of the $\xi$ potential was $<0.025$ $\mathrm{V}$, or by means of interpolation between the values of the Verwey and Overbeek tabulated values. ${ }^{24}$ Steric stabilization was not taken into account: two particles were regarded as coagulated if the distance between the surfaces of two particles became twice the polyelectrolyte layer thickness.

The calculations were first performed in the absence of an adsorbed PAA layer, again taking into account retar-

(23) Osmond, D. W. J.; Vincent, B.; Waite, F. A. J. Colloid Interface Sci. 1973, 42, 262.

(24) Overbeek, J. Th. G. In Colloid Science; Kruyt, H. R., Ed.; Elsevier Publishing Co.: Amsterdam, 1952; Vol I, p 254.

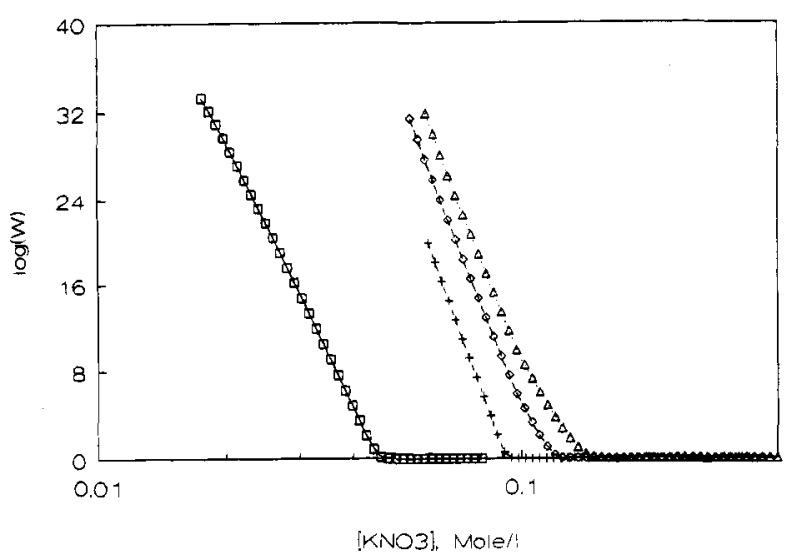

Figure 11. Theoretical electrostatic stability ratios, in the absence and presence of an adsorbed PAA layer with thickness varying between $0.1 \mathrm{~nm}$ at $\left[\mathrm{KNO}_{3}\right]=0.4 \mathrm{M}$ to $1 \mathrm{~nm}$ at $\left[\mathrm{KNO}_{3}\right]$ $=0.1 \mathrm{M}$. Stern potentials are assumed to be equal to the $\zeta$ potentials. $\diamond$, Hamaker constant $=0.5 \times 10^{-20} \mathrm{~J}$, surface without polyelectrolyte layer; $\triangle$, Hamaker constant $=0.5 \times$ $10^{-20} \mathrm{~J}$, surface with layer; $\square$, Hamaker constant $=5 \times 10^{-20}$ $\mathrm{J}$, surface without layer; + , Hamaker constant $=5 \times 10^{-20} \mathrm{~J}$, surface with layer.

dation of attraction. This gives the two curves in Figure 11 referred to as "surface without layer". The curves related to situations with an adsorbed PAA layer were calculated in the same way, but on the assumption that in this case the $\zeta$ potential could be used as an approximation for the electrical potential at the outer boundary of the hydrodynamic layer. A hydrodynamic layer thickness was assumed varying from $0.1 \mathrm{~nm}$ in 0.4 M 1:1 electrolyte solution to $1 \mathrm{~nm}$ in $0.1 \mathrm{M}$ solution. This leads to the other two curves in Figure 11. It is seen that, on the basis of these assumptions, a distinct retardation of aggregation is calculated for both values of the Hamaker constant, especially for a Hamaker constant of $5 \times 10^{-20}$ J.

\section{Summary}

Polyacrylic acid (MW 2000) effectively stabilizes $\mathrm{TiO}_{2}$ dispersions against aggregation, both in dilute dispersions (solid volume fraction $\phi=2.5 \times 10^{-7}$ ) and in concentrated ones $(\phi=0.16-0.19)$.

The apparent viscosity of $\mathrm{TiO}_{2}$ dispersions, in the high $\phi$ range investigated, is found to have a complicated pattern as a function of the quantity of PAA added: small quantities of PAA increase the viscosity by causing bridging aggregation; larger quantities stabilize the dispersion, which leads to a decrease in viscosity; still larger quantities increase the viscosity slightly again, presumably by increasing the hydrodynamic radius of the dispersed particles through an adsorbed PAA layer.

LA9400363 